\title{
GCU
}

Glasgow Caledonian

University

University for the Common Good

\section{The technique of delivery of peri-operative analgesia does not affect the rehabilitation or outcomes following total knee arthroplasty}

McDonald, D. A.; Deakin, A.H.; Ellis, B.M.; Robb, Y.; Howe, T.E.; Kinninmonth, A.W.G.; Scott, N.B.

Published in:

Bone and Joint Journal

DOI:

10.1302/0301-620X.98B9.36250

Publication date:

2016

Document Version

Author accepted manuscript

Link to publication in ResearchOnline

Citation for published version (Harvard):

McDonald, DA, Deakin, AH, Ellis, BM, Robb, Y, Howe, TE, Kinninmonth, AWG \& Scott, NB 2016, 'The technique of delivery of peri-operative analgesia does not affect the rehabilitation or outcomes following total knee arthroplasty', Bone and Joint Journal, vol. 98-B, no. 9, pp. 1189-1196. https://doi.org/10.1302/0301$620 X .98 B 9.36250$

\section{General rights}

Copyright and moral rights for the publications made accessible in the public portal are retained by the authors and/or other copyright owners and it is a condition of accessing publications that users recognise and abide by the legal requirements associated with these rights.

Take down policy

If you believe that this document breaches copyright please view our takedown policy at https://edshare.gcu.ac.uk/id/eprint/5179 for details of how to contact us. 
Peri-operative analgesic method does not affect rehabilitation outcomes following total knee arthroplasty.

D A McDonald (Prof D, BSc) - Clinical Researcher, Department of Rehabilitation, Golden Jubilee National Hospital, Agamemnon St, Clydebank, Scotland, G81 4DY.

A H Deakin (PhD) - Orthopaedic Audit \& Research Manager, Department of Orthopaedics, Golden Jubilee National Hospital, Agamemnon St, Clydebank, Scotland, G81 4DY

B M Ellis (PhD) - Deputy Director, Graduate School, Glasgow Caledonian University, Cowcaddens Road, Glasgow, Scotland, G4 0BA

Y Robb (PhD) - Lecturer, School of Health \& Life Sciences, Glasgow Caledonian University, Cowcaddens Road, Glasgow, Scotland, G4 0BA

T E Howe (PhD) - Professor of Rehabilitation, School of Health \& Life Sciences, Glasgow Caledonian University, Cowcaddens Road, Glasgow, Scotland, G4 0BA

A W G Kinninmonth (FRCS) - Consultant Orthopaedic Surgeon Department of Orthopaedics, Golden Jubilee National Hospital, Agamemnon St, Clydebank, Scotland, G81 4DY

N B Scott (FRCA, FRCS) - Consultant Anaesthetist, Department of Anaesthesia, Golden Jubilee National Hospital, Agamemnon St, Clydebank, Scotland, G81 4DY 


\section{ABSTRACT}

This non-blinded randomised controlled trial compared the effect of patient controlled epidural $\underline{\text { analgesia (PCEA) versus local infiltration analgesia (LIA) within an established Enhanced }}$ $\underline{\text { Recovery Programme on attainment of discharge criteria and recovery at one year following }}$ surgery. The hypothesis was that LIA would increase the proportion of patients discharged from $\underline{\text { rehabilitation by post-operative day four but not affect outcomes at one year. } 242 \text { patients were }}$ randomized with 109 patients receiving PCEA (mean age 66 SD (11)) and 113 receiving LIA (mean age 68 SD (10)). Patients were followed up at six weeks and one year. No difference was noted in the proportion of patients discharged from rehabilitation by post-operative day 4, PCEA $=77 \%$ vs. LIA $=82 \%(p=0.33)$ or mean length of stay (both 4 days, $p=0.540)$. No difference was observed in day of first mobilisation $(\mathrm{p}=0.013)$ or pain scores $(\mathrm{P}=0.278)$. At one year follow up there were no differences in Oxford Knee Scores (both 41, $\mathrm{p}=0.915$ ) or complication rates (two vs. six, $\mathrm{p}=0.281$ ). Both techniques provided adequate pain relief, enabled early ambulation and accelerated rehabilitation and continued improvement in functional and patient reported outcomes up to one year following surgery. PCEA and LIA enable equitable clinical outcomes following TKA. 


\section{INTRODUCTION}

Enhanced Recovery Programmes (ERP) following total knee arthroplasty (TKA) have demonstrated reductions in both morbidity and mortality ${ }^{1-3}$ Their implementation has included several major alterations in clinical practice simultaneously and therefore it is difficult to ascertain which component(s) of the programme may be most significant in the improvements

${ }^{4}{ }^{4}$.eported . Emerging evidence supports both pre-operative education ${ }^{5,6}$ and accelerated rehabilitation $^{7}$, however the optimum method(s) of multimodal analgesia throughout the peri8

operative period remains unclear . Regional analgesic techniques have demonstrated improvements in pain control and outcomes following TKA compared to opioid analgesia alone ${ }^{9,10}$. However, they are associated with rare major risk factors such as spinal haematoma for epidurals $^{11}$ and prolonged motor blockade and falls in femoral nerve blocks ${ }^{12,13}$ which may hinder early ambulation and delay rehabilitation ${ }^{13,14}$. The effect of these regional analgesic techniques on rehabilitation outcomes and long term follow up is poorly understood ${ }^{9,15}$.

Local Infiltration Analgesia (LIA) has been reported as an alternative analgesic regime with a

number of studies demonstrating equitable or improved outcomes compared to opioid analgesia $14,17-21$

and other regional anaesthetic techniques . However due to the varying cocktail of infiltration medicines, the volume of infiltrate and limited number of high quality evidence studies comparing two regional techniques which allow early ambulation, it is difficult to draw 22 comparisons and extrapolate the findings . Furthermore, there is a lack of data from randomised 
trials looking at long-term follow up.

The aim of this study was to compare the effect of two regional analgesic techniques, patient controlled epidural analgesia (PCEA) versus local infiltration analgesia (LIA) within an established Enhanced Recovery Programme to ascertain their impact on attainment of rehabilitation discharge criteria and outcomes at six weeks and one-year post-surgery.

The primary outcome measure was the proportion of patients discharged from rehabilitation on post-operative day 4 (POD 4). Secondary outcome measures included in-patient data: verbal rated pain scores (VRS); use of additional rescue analgesia; post-operative urinary catheterisation rates; ambulation rates on the day of theatre; length of hospital stay; and rehabilitation outcomes: Oxford Knee Scores and complication rates at six weeks and one-year post-surgery.

\section{PATIENTS AND METHODS}

The study was a randomised controlled parallel group trial with an equal allocation ratio. Ethical approval was obtained from the West of Scotland Research Ethics Committee (NRES:09/S10014/56). The study was conducted in accordance with the Declaration of Helsinki and conformed to the CONSORT Guidelines and has been registered at clinicaltrial.gov (NCT02478372). From April 2010-August 2011 patients aged over 18 years undergoing primary unilateral TKA for osteoarthritis were considered eligible for inclusion into the study. Exclusion criteria included: patients listed for uni-compartmental/bilateral or revision knee surgery, a diagnosis of rheumatoid arthritis, coagulation or anatomical defects preventing the use of spinal anaesthesia or known allergies to any medications within the trial, inability to give written 
consent, requiring pre- operative catheterisation for urinary outflow dysfunction and a known neurological incident that would limit or make impossible early mobilisation following surgery. Written and informed consent for the trial was obtained on the day prior to surgery. Participation within the trial ended following the routine one-year follow-up appointment.

A simple unrestricted (non-block) randomisation method was used to generate the random allocation sequence. Patients were randomised to either patient controlled epidural analgesia (PCEA) or local infiltration analgesia (LIA). Randomisation was carried out using sequentially 24

numbered opaque sealed envelopes. Once written informed consent was obtained by the surgeon, the anaesthetist in charge of the patient's care collected the next numbered envelope on the morning of surgery.

All patients received standardised peri-operative care. This included pre-operative education in the form of written information, an education class and exercise DVD. All patients received the pre- operative and post-operative analgesic regime in Table 1. Surgery was performed under spinal via the $\mathrm{L} 2 / 3$ or $\mathrm{L} 3 / 4$ interspaces using $2.5 \mathrm{ml}$ hyperbaric bupivacaine $5 \mathrm{mg} . \mathrm{ml}-1$ supplemented by a target-controlled infusion of propofol to maintain sedation. In the event of a general anaesthesia being required because of failed spinal anaesthesia, the patient was excluded from the trial. Tranexamic acid ( $2.5 \mathrm{~g})$ was administered intravenously to minimise postoperative blood loss. A medial parapatellar or lateral parapatellar arthrotomy under tourniquet was used_as per surgeon preference. Cemented implants were as per surgeon preference (Triathlon $^{\mathrm{TM}}$, Stryker, Michigan, USA or Columbus ${ }^{\mathrm{TM}}$, BBraun Medical Ltd. Melsungen, Germany).

The PCEA group had a catheter sited between L1 and L3 pre-operatively. They received 4ml of 
2.5 mg.ml-1 levobupivacaine at the end of surgery prior to leaving the operating room.

Thereafter they self-medicated with $2 \mathrm{ml}$ of $1.25 \mathrm{mg} . \mathrm{ml}-1$ bupivacaine via a Patient Controlled Epidural Analgesia (PCEA) system (BodyGuard Colourvision 545 ${ }^{\mathrm{TM}}$ Epidural Infusion Pump

(CME Medical UK Limited, Blackpool, UK)) with a lockout of 15 minutes until 8 a.m. the following morning (post-operative day one) when it was stopped. Nurse-administered rescue topups of $4 \mathrm{ml}$ of $2.5 \mathrm{mg} . \mathrm{ml}-1$ levobupivacaine were available for inadequate analgesia.

The LIA group received standardised intra-articular and subcutaneous infiltration during surgery using a total of $200 \mathrm{ml}$ of $2 \mathrm{mg} . \mathrm{ml}-1$ ropivacaine (Naropin ${ }^{\circledR}$, AstraZeneca, Sweden) without 3 adrenaline or additives . $50 \mathrm{ml}$ was injected following bone preparation parallel to the posterior femur through the posterior joint capsule in even $10 \mathrm{ml}$ aliquots. $30 \mathrm{ml}$ was inserted through the skin proximal to the suprapatellar pouch down to the level of the femur. $100 \mathrm{ml}$ was spread around the subcutaneous tissues including the collateral ligaments and cruciate ligaments (when preserved) and fatty and connective tissue on the anterior aspect of the incision. A 16-gauge epidural catheter (BBraun Medical Ltd. Melsungen, Germany) was inserted via a medial portal several centimetres from the wound and passed into the posterior region of the knee. Finally, $20 \mathrm{ml}$ was injected via the catheter following closure of the surgical wound. The catheter was then capped off and a bacterial epidural filter applied.

On return to the ward, patients received nurse-administered boluses of $40 \mathrm{ml} 2 \mathrm{mg} . \mathrm{ml}-1$ ropivacaine via a BodyGuard 595 ${ }^{\mathrm{TM}}$ Regional Analgesia Infusion Pump (CME Medical UK Limited, Blackpool, UK) four hours after leaving theatre, at 22:00 and then at 08:00 on the morning of post-operative day one, after which the catheter was removed. In the event of uncontrolled pain two additional top ups of $40 \mathrm{ml} 2 \mathrm{mg} . \mathrm{ml}-1$ ropivacaine were prescribed if 
required within this time frame. All wounds were closed with sutures or clips and standard 25

dressings applied Prior to $6 \mathrm{pm}$ on the day of theatre, all patients were reviewed by a physiotherapist to begin ambulation. Pain scores in the form of summary 24-hour verbal rating scores (VRS) ${ }^{26}$ were collected for the first three post-operative days as were daily nausea and vomiting scores as per the standard care in our institution at the time. The usage of PRN analgesia, post-operative urinary catheterisation rates and the reason for catheterisation were also recorded. From post-operative day (POD) one patients were reviewed daily by rehabilitation staff and were discharged from rehabilitation once they had achieved established standardised discharge criteria (Table 2) ${ }^{3}$. Maximum flexion angle achieved at discharge from rehabilitation was measured using a hand held goniometer . Patients who were unable to achieve the required flexion or demonstrate a return of sufficient quadriceps muscle strength after day five postsurgery were referred on to outpatient physiotherapy. All patients were discharged directly home.

Patients attended routine independent arthroplasty follow up clinic appointments at six weeks and one year after surgery. Oxford Knee Scores (OKS, 0 to 48 scale) and maximum flexion were recorded. Any adverse events whilst patients were in hospital following surgery were recorded. Transfusion policy was a haemoglobin of $<=8 \mathrm{~g} / \mathrm{dL}$ or if significant symptoms of anaemia developed. Information Services Division (ISD) NHS Scotland, provided complication data based on readmission to any hospital in Scotland. up to one-year post surgery. They also provided mortality data.

Statistics

Preliminary data demonstrated that $49 \%$ patients (22/45) receiving PCEA could be discharged 
from rehabilitation by POD 4 compared to $75 \%$ (40/53) who had LIA. Therefore, to achieve a $90 \%$ power at a $1 \%$ significance level with $50 \%$ discharged in PCEA group and $75 \%$ in the LIA group it was calculated that the study would require 110 patients in each arm. Allowing for a $10 \%$ fall out rate, it was intended to recruit 121 patients into each arm of the study. Due to the large number of secondary outcome measures statistical significance was set at $\mathrm{p}<0.01$.

Statistical analysis was performed using SSPS version 19 (SPSS Inc., Chicago, IL, USA). Data were analysed on a per protocol basis. The primary outcome for the study was assessed using a Chi- squared test. The secondary outcomes of length of stay, post-operative mobilisation and post- operative catheterisation were assessed using a Chi-squared test. Pain scores, use of PRN analgesia, maximal flexion at discharge and follow up along with OKS were not normally distributed so were assessed with a Mann-Whitney test. Due to the small numbers of complication data, a Fishers Exact Test was used.

\section{RESULTS}

308 patients attending the outpatient appointment were assessed for eligibility to the trial (Figure 1). A total of 242 patients were recruited and randomised to the two groups (121 patients per group). Demographic data for all randomised patients were similar between groups (Table 3). Twenty patients were excluded from the analysis, 12 in the PCEA group and eight in the LIA group, all due to failed spinal anaesthesia.

For the PCEA $(n=109)$ and LIA $(n=113)$ groups no difference was observed between the proportions of patients discharged from rehabilitation by POD $4 \mathrm{p}=0.332$ (Table 4 , Figure 2 ). No differences in the time (days) to achieve the discharge criteria, length of hospital stay, pain VRS, the PRN analgesia usage or incidence of nausea and vomiting, maximum knee flexion on 
discharge or proportion of patients sent for further outpatient physiotherapy were seen (Table 4). One patient within each group required a PCA morphine pump to be started due to poor pain control on post-operative day one.

A higher proportion of patients within the LIA group were able to ambulate for the first time on the afternoon of theatre however this was not statistically significant based on our a-priori criterion of $\mathrm{p}<0.01$ (Table 4). All patients within the LIA group had ambulated within 24 hours of surgery but four patients within the PCEA group did not achieve this until the morning of post-operative day two. The main reason for failed ambulation on theatre day was an unresolved spinal anaesthesia block resulting in motor weakness preventing safe ambulation.

At six weeks and one year follow up no statistically significant difference were observed in outcomes (Table 5). Up to one-year post-operation the PCEA group had two complications (one wash-out for suspected infection and one acute myocardial infarction) and the LIA group had six (one gastro-intestinal bleed, two suspected infections, one renal failure, two deaths (causes unknown $(\mathrm{p}=0.281)$. 


\section{DISCUSSION}

This study demonstrated no differences between the proportion of patients obtaining set discharge criteria by POD 4 following a primary TKA within an established Enhanced Recovery Programme whether PCEA $(77.1 \%)$ or LIA $(82.3 \%)$ analgesia was used. Similarly, the median $\underline{\text { time to attain discharge criteria ( } 3 \text { days) and total post-operative stay (4 days) showed no }}$ difference between groups. These findings are contrary to two previous randomised trials of continuous epidural and LIA following TKA ${ }^{14,29}$. Although the time to attain discharge criteria for the LIA groups was similar to our trial, the times within the epidural groups was much greater ( 5.5 and 4 days respectfully vs. 3 in our study). In both previous studies the epidural regimes were in-situ for 48 hours and had a continuous background infusion of between $4-10$ $\mathrm{ml} / \mathrm{hr}$ running delaying early ambulation and commencement of rehabilitation post-surgery. Within the present trial the PCEA regime had no background rate infusion and was stopped on the morning of post-operative day one at 8a.m. To our knowledge this is the first trial to utilise a PCEA regime with no background infusion that enabled early safe ambulation and commencement of rehabilitation and provided a greater comparator technique to the LIA than previous trial designs. Two recent trials compared PCEA +FNB versus LIA ${ }^{19,20}$ and report a similar timeframe to attainment of discharge criteria for both groups within their trial and the current trial (3.2 days each). However, due to limited detail of the specific method including volume and timing of the PCEA +FNB under investigation, it is difficult to compare these results to the PCEA method and findings within the current trial.

Both PCEA and LIA techniques provided good analgesia comparable to that achieved following $17,19,21$

femoral nerve block for the first 24 and 48-hour period following surgery. We have 
demonstrated equitable pain control and outcomes using only local anaesthetic with no additives compared to other randomised trials comparing LIA and continuous epidural regimes with $\underline{\text { additives included (i.e. }+/ \text { - morphine, NSAIDS, steroids and epinephrine) }}{ }^{14,29,30}$. The extrapolation from this is that these additives may be unnecessary for either infiltration or epidural administration and raises further questions around the benefits of the numerous cocktails 31 used . However, to confirm this other trials directly comparing regimes are required.

The use of LIA boluses following the large volume infiltration in theatre was facilitated via an indwelling catheter until the morning (8a.m.) of post-operative day one. Several literature reviews suggest that there is insufficient evidence for catheters following large volume injection in theatre ${ }^{22,32}$. However recent studies support our findings that there does appear to be further benefit in enabling better pain control within the first 24 hours and possibly beyond this $\operatorname{period}^{33,34}$.

Early ambulation demonstrates both physiological benefits in reducing complications and improving satisfaction with pain control whilst shortening length of hospital stay following 3 TKA . No statistical difference was noted between the two groups in the proportion of patients ambulated on theatre day or within 24 hour following surgery. The main reasons for delays in ambulation on theatre day were a dense bilateral residual motor blockade from the spinal anaesthetic or that the patient had not returned from theatre. No incidence of transient peroneal nerve palsy was observed within the LIA group compared to other studies which report an incidence of $12 \%{ }^{30}$. 
The changes in OKS over the 12-month period (PCEA=24(-20-38) vs. LIA=22(-3-40), $\mathrm{p}=0.640)$ suggests an above average predicted improvement compared to published literature (predicted improvement in score $=18.4(9.5))^{28}$. The improvement in score is also better than previous 3 published data from our hospital . The reason for this is difficult to ascertain as no fundamental changes were made to the Enhanced Recovery Programme.

Of major concern with the use of the LIA technique and specifically an indwelling catheter is the risk of infection ${ }^{37}$. Although two patients were recorded as having a wound infection with one patient returning to theatre for a lavage, no difference was observed between groups $(\mathrm{p}=1.000)$. The reported incidence (1.7\%) of wound infection with the use of a wound catheter is the same $(1.7 \%)$ as a large cohort series $(n=1081)$ from the same hospital and considerably lower than 38

rates (11\%) reported by a recent trial from Scandinavia . No deaths within 30 days of surgery were recorded within either group. Two deaths were recorded at one-year post-surgery within the LIA group, the cause of death was unknown. It is unlikely these were related directly to the surgical intervention or methods of analgesia under investigation within this trial. These findings support the efficacy and safety of both techniques however as this study was not powered specifically to look at complications, further large-scale cohort studies specifically powered to look at each adverse incident in more detail with the use of these techniques are required.

As with all randomised controlled trials this study has some limitations. It was not blinded which may have introduced some reporting bias. A large number of surgeons $(n=11)$ were involved in the recruitment and consenting of patients and as a result, a large cohort of eligible patients were not approached during the pre-operative assessment clinics. To conform to the ethical 
submission and trial protocol, only patients who had been identified by the Consultant surgeon, were eligible for inclusion within the current study. This could have introduced performance bias into the patients included within the study cohort. However, trial demographics for each group are very similar to a large consecutive cohort from within the same institution and appears representative of the standard population attending for TKA surgery within Scotland ${ }^{39}$. In addition, the exclusion criteria mean that this trial did not include the whole TKA population. There are a minority of patients who cannot have a spinal anaesthetic for clinical reasons and the results of this study cannot be applied to this group. Similarly, we excluded those requiring preoperative catheterisation as we wished to accurately identify the need for post-operative catheterisation in each group and with particular reference to the epidural group. Therefore, it is not known whether these results would be seen in these patients. However this study was more inclusive than previously reported trials $^{14,29}$. A further limitation is that the time for which patients received analgesia would vary dependent on where they were on the theatre list. This was true for both groups. However, both groups had similar distributions of positions on the list so we do not feel this affected the results in terms of differences between the groups. Further work is required to ascertain how much difference the position on the list makes to analgesia efficacy. The fact that the study data did not conform to the preliminary data used for the power calculation means that the small differences seen in the primary outcome were not significant. This current study demonstrates why conclusions on small sample sizes should not be drawn. The preliminary data was collected during the introduction of the PCEA as compared to a traditional continuous epidural with a background rate limiting ambulation which had been standard care within our institution. The potential learning curve of staff in mobilising patients early with epidurals may have contributed to the preliminary data and resultant power 
calculation.

This randomised control trial demonstrates that the methods of patient controlled peri-operative regional analgesia, PCEA and LIA, used within the current trial do not affect the time taken to reach standardised discharge criteria within an established Enhanced Recovery Programme. Both techniques provided adequate pain relief and enabled early ambulation and accelerated rehabilitation and continued improvement in functional and patient reported outcomes up to one year following surgery. 


\section{REFERENCES}

1. Savaridas T, Serrano-Pedraza I, Khan SK, Martin K, Malviya A, Reed M.R., Reduced medium-term mortality following primary total hip and knee arthroplasty with an enhanced recovery program. Acta Orthopaedica 2013; 84: 40-43.

2. Malviya A, Martin K, Harper I, Muller SD, Emmerson KP, Partington PF, et al. Enhanced recovery program for hip and knee replacement reduces death rate. Acta Orthopaedica 2011; 82: 577-581.

3. McDonald DA, Siegmeth R, Deakin AH, Kinninmonth AWG, Scott NB. An enhanced recovery programme for primary total knee arthroplasty in the United Kingdom — follow up at one year. The Knee 2012; 19: 525-529.

4. Wainwright T, Middleton R. An orthopaedic enhanced recovery pathway. Current Anaesthesia \& Critical Care. 2010; 21: 114-120.

5. Huang SW, Chen PH, Chou YH. Effects of a preoperative simplified home rehabilitation education program on length of stay of total knee arthroplasty patients. Orthopaedics \& Traumatology, Surgery \& Research 2012; 98: 259-264.

6. Jones S, Alnaib M, Kokkinkis M, Wilkinson M, St Clair Gibson A, Kader D. Preoperative patient education reduces length of stay after knee joint arthroplasty. Annuals Royal College Surgeons England 2011; 93: 71-75 
7. Larsen K, Sørensen O, Hansen TB, Thomsen PB, Søballe K. Accelerated perioperative care and rehabilitation intervention for hip and knee replacement is effective: A randomized clinical trial involving 87 patients with 3 months of follow-up. Acta Orthopaedica 2012; 79: 149-159.

8. Kehlet $\mathrm{H}$, Thienpont E. Fast-track knee arthroplasty - status and future challenges. The Knee 2013; 20: S29-S33

9. Wu CL, Cohen SR, Richman JM, Rowlingson AJ, Courpas GE, Cheung K, et al. Efficacy of postoperative patient-controlled and continuous infusion epidural analgesia versus intravenous patient-controlled analgesia with opioids: A meta-analysis. Anesthesiology 2005; 103: 1079-88

10. Paul JE, Arya A, Hurlburt L, Cheng J, Thabane L, Tidy A, et al. Femoral nerve block improves analgesia outcomes after total knee arthroplasty: A meta-analysis of randomized controlled trials. Anesthesiology, 2010; 113: 1144-62

11. Cook TM, Counsell D, Wildsmith JAW. Major complications of central neuraxial block: Report on the third national audit project of the royal college of anaesthetists. British Journal of Anaesthesia, 2009; 102: 179-190.

12. Ilfeld BM, Duke KB, Donohue MC. The association between lower extremity continuous peripheral nerve blocks and patient falls after knee and hip arthroplasty. Anesthesia and Analgesia 2010; 111: 1552-1554.

13. Sharma S, Iorio R, Specht L, Davies-Lepie S, Healy W. Complications of femoral nerve block for total knee arthroplasty. Clinical Orthopaedics and Related Research ${ }^{\circledR} 2010$; 468: $135-140$. 
14. Spreng UJ, Dahl V, Hjal, A, Fagerland MW, Raeder J. High-volume local infiltration analgesia combined with intravenous or local ketorolac compared with epidural analgesia after total knee arthroplasty. British Journal of Anaesthesia, 2010; 105: 675-682.

15. Choi P, Bhandari M, Scott J, Douketis James D. Epidural analgesia for pain relief following hip or knee replacement. 2003 John Wiley \& Sons, Ltd.

16. Xu CP, Li X, Wang ZZ, Song JQ, Yu B. Efficacy and safety of single-dose local infiltration of analgesia in total knee arthroplasty: A meta-analysis of randomized controlled trials. The Knee 2014; $21: 636-46$

17. Toftdahl K, Nikolajsen L, Haraldsted V, Madsen F, Tønnesen E, Søballe K. Comparison of peri- and intraarticular analgesia with femoral nerve block after total knee arthroplasty: A randomized clinical trial. Acta Orthopaedica, 2007; 78: 172-179.

18. Parvataneni HK, Shah VP, Howard H, Cole N, Ranawat AS, Ranawat CS. Controlling pain after total hip and knee arthroplasty using a multimodal protocol with local periarticular injections: A prospective randomized study. The Journal of Arthroplasty, 2007; 22: 33-38.

19. Meftah M, Wong AC, Nawabi DH, Yun RJ, Ranawat AS, Ranawat CS. Pain management after total knee arthroplasty using a multimodal approach. Orthopedics, 2012; 35: 660-4.

20. Yadeau JT, Goytizolo EA, Padgett DE, Liu SS, Mayman DJ, Ranawat AS, et al. Analgesia after total knee replacement: Local infiltration versus epidural combined with a 
femoral nerve blockade: A prospective, randomised pragmatic trial. The Bone \& Joint Journal, 2013; 95: 629-635.

21. Carli F, Clemente A, Asenjo JF, Kim DJ, Mistraletti G, Gomarasca M, et al. Analgesia and functional outcome after total knee arthroplasty: Periarticular infiltration vs continuous femoral nerve block", British Journal of Anaesthesia, 2010; 105: 185-195.

22. Anderson LO, Kehlet H. Analgesic efficacy of local infiltration analgesia in hip and knee arthroplasty: a systematic review. British Journal of Anaesthesia 2014;113: 360-374

23. Moher D, Hopewell S, Schulz KF, Montori V, Gøtzsche PC, Devereaux PG, et al. CONSORT 2010 explanation and elaboration: Updated guidelines for reporting parallel group randomised trials. British Medical Journal 2010; 340: c332 .

24. Doig GS, Simpson F. Randomization and allocation concealment: A practical guide for researchers. Journal of Critical Care, 2005; 20: 187-191.

25. Clarke JV, Deakin AH, Dillon JM, Emmerson S, Kinninmonth A. A prospective clinical audit of a new dressing design for lower limb arthroplasty wounds. Journal of Wound Care, 2009; 18: 5-8

26. Jensen MP, Mardekian J, Lakshminarayanan M, Boye ME. Validity of 24-h recall ratings of pain severity: Biasing effects of "peak" and "end" pain". Pain, 2008; 137: 422-427.

27. Lenssen AF, van Dam EM, Crijns YH, Verhey M, Geesink RJ, van den Brandt PA, et al. Reproducibility of goniometric measurement of the knee in the in-hospital phase following total knee arthroplasty. BMC Musculoskeletal Disorders 2007; 8: 83-89 
28. Murray DW, Fitzpatrick R, Rogers K, Pandit H, Beard DJ, Carr AJ, et al. The use of the oxford hip and knee scores", The Journal of Bone and Joint Surgery.British Volume, 2007; 89: 1010-1014.

29. Andersen KV, Bak M, Christensen BV, Harazuk J, Pedersen NA, Soballe K. A randomized, controlled trial comparing local infiltration analgesia with epidural infusion for total knee arthroplasty. Acta Orthopaedica 2010; 81: 606-610.

30. Tsukada S, Wakui M, Hoshino A. Postoperative Epidural Analgesia Comparedd with Intraoperative Periarticular Injection for Pain Control Following Total Knee Arthroplasty Under Spinal Anaesthesia. The Journal of Bone and Joint Surgery 2014; 96: 1433-8

31. Rawal N. Local infiltration analgesia and other multicomponent techniques to improve postoperative outcome--are we comparing oranges and apples. Regional Anesthesia and Pain Medicine 2011; 36: 417-420.

32. Gibbs DM, Green TP, Esler CN. The local infiltration of analgesia following total knee replacement: A review of current literature. The Journal of Bone and Joint Surgery. British Volume 2012; 94: 1154-1159.

33. Weston-Simons JS, Pandit H, Haliker V, Dodd CA, Popat MT, Murray DW. Intraarticular local anaesthetic on the day after surgery improves pain and patient satisfaction after unicompartmental knee replacement: A randomised controlled trial. The Knee 2012; 19:352-355.

34. Goyal N, McKenzie J, Sharkey PF, Parvizi J, Hozack WJ, Austin MS. The 2012 chitranjan ranawat award: Intraarticular analgesia after TKA reduces pain: A randomized, 
double-blinded, placebo-controlled, prospective study. Clinical Orthopaedics and Related Research, 2012; 471: 64-75.

35. Pearse EO, Caldwell BF, Lockwood RJ, Hollard J. Early mobilisation after conventional knee replacement may reduce the risk of postoperative venous thromboembolism. The Journal of Bone and Joint Surgery.British Volume, 2007; 89: 316-322.

36. Lunn TH, Kristensen BB, Gaarn-Larsen L, Kehlet H. Possible effects of mobilisation on acute post-operative pain and nociceptive function after total knee arthroplasty. Acta Anaesthesiologica Scandinavica, 2012; 56: 1234-1240

37. Marques EM, Jones HE, Elvers KT, Pyke M, Blom AW, Beswick AD. Local anaesthetic infiltration for peri-operative pain control in total hip and knee replacement: systematic review and meta-analyses of short- and long-term effectiveness. BMC Musculoskeletal Disorders 2014; 15: 220

38. Ali A, Sundberg M, Hansson U, Malmvik J, Flivik G. Doubtful effect of continuous intraarticular analgesia after total knee arthroplasty. Acta Orthopaedica. 2015; 86: x-x 1. Epub ahead of print

39. No author listed. Scottish Arthroplasty Project: Biennial Report, 2014. http://www.arthro.scot.nhs.uk/docs/2014-08-12-SAP-Report.pdf?2 (date last accessed $1^{\text {st }}$ July 2015). 
Table 1 Peri-operative Analgesia Regimen

\begin{tabular}{ll} 
Time & Multimodal Analgesic Regime \\
\hline Oral pre-medication & $10-20 \mathrm{mg}$ Temazepam \\
(2 h before surgery) & $150 \mathrm{mg}$ Ranatidine \\
& $10 \mathrm{mg}$ Dexamethasone \\
& $300 \mathrm{mg}$ Gabapentin \\
& $1 \mathrm{~g}$ Paracetamol \\
& $300 \mathrm{mg}$ Gabapentin twice daily for 5 days \\
& $1 \mathrm{~g}$ Paracetamol 4 times daily \\
Post-operative & $400 \mathrm{mg}$ Ibuprofen 3 times daily \\
& $10 \mathrm{mg}$ Oxycontin $\AA$ 12 hourly for 3 doses \\
& $5-10 \mathrm{mg}$ Oxynorm $\AA 2-4$ hourly as required \\
& \\
\hline
\end{tabular}


Table 2. Standardised Rehabilitation Discharge Criteria

\section{Standardised Discharge Criteria}

Independent (able to dress and personal care)

Ability to transfer independently on/off bed/chair/toilet/stairs

$80^{\circ}$ flexion of the operated knee joint

Ability to straight leg raise operated limb with minimal lag in extension 
Table 3: Demographic data of all randomised patients and patients excluded following randomisation. Data presented as median (inter quartile range).

\begin{tabular}{|c|c|c|c|c|}
\hline & \multicolumn{2}{|c|}{ Randomised Patients } & \multicolumn{2}{|c|}{$\begin{array}{c}\text { Patients excluded following } \\
\text { randomisation }\end{array}$} \\
\hline & PCEA & LIA & $\begin{array}{l}\text { Excluded Pts } \\
\text { PCEA }\end{array}$ & $\begin{array}{l}\text { Excluded } \\
\text { Pts LIA }\end{array}$ \\
\hline $\mathrm{N}$ & 121 & 121 & 12 & 8 \\
\hline Age & $66(11)$ & $68(10)$ & $67(13)$ & $70(10)$ \\
\hline BMI & $31(8)$ & $31(8)$ & $35(9)$ & $30(5)$ \\
\hline Gender-Males & $46 \%$ & $41 \%$ & $36 \%$ & $33 \%$ \\
\hline Operative side - Left & $50 \%$ & $58 \%$ & $63 \%$ & $66 \%$ \\
\hline Pre-Operative OKS & 17 & 17 & & \\
\hline ASA 1 & $11 \%$ & $18 \%$ & 0 & $12.5 \%$ \\
\hline ASA 2 & $67 \%$ & $66 \%$ & $75 \%$ & $75 \%$ \\
\hline ASA 3 & $22 \%$ & $15 \%$ & $25 \%$ & $12.5 \%$ \\
\hline ASA 4 & $0 \%$ & $1 \%$ & 0 & 0 \\
\hline
\end{tabular}

ASA=American Society of Anaesthesia Score 
Table 4: In-patient data for all included patients. Data presented as median (IQR) [range].

\begin{tabular}{|c|c|c|c|}
\hline & $\begin{array}{l}\text { PCEA } \\
n=109\end{array}$ & $\begin{array}{c}\text { LIA } \\
n=113\end{array}$ & P value \\
\hline D/C from rehabilitation by POD $4^{\S}$ & $77 \%$ & $82 \%$ & 0.332 \\
\hline Days to $\mathrm{D} / \mathrm{C}$ from rehabilitation & $3[1-20]$ & $3[1-8]$ & 0.755 \\
\hline Length of stay (days) & $4[2-20]$ & $4[2-12]$ & 0.554 \\
\hline Post-Op Urinary Catheterisation $(\%)^{\S}$ & $9.2 \%$ & $4.4 \%$ & 0.159 \\
\hline \multicolumn{4}{|l|}{ Verbal Rating pain Score (VRS) } \\
\hline VRS POD $0^{\ddagger}$ & $3(4)$ & $3(4)$ & 0.278 \\
\hline VRS POD $1^{\ddagger}$ & $3(3)$ & $4(3)$ & 0.041 \\
\hline VRS POD $2^{\ddagger}$ & $3(2)$ & $4(3)$ & 0.319 \\
\hline \multicolumn{4}{|l|}{ Oxynorm usage (10mg Dose) } \\
\hline POD $1^{*}$ & $1[0-6]$ & $1[0-5]$ & 0.896 \\
\hline POD $2 *$ & $2[0-7]$ & $2[0-9]$ & 0.336 \\
\hline POD $3^{\ddagger}$ & $1[0-6]$ & $0[0-5]$ & 0.773 \\
\hline Total usage ${ }^{*}$ & $4[0-15]$ & $4[0-15]$ & 0.554 \\
\hline Post-Op Nausea and Vomiting & $16 \%$ & $14 \%$ & \\
\hline \multicolumn{4}{|c|}{ Proportion of patients ambulating (Cumulative \%) } \\
\hline Theatre Day ${ }^{\S}$ & $35 \%$ & $51 \%$ & 0.013 \\
\hline POD $1^{\S}$ & $96 \%$ & $100 \%$ & 0.040 \\
\hline$>24$ hours post-surgery & $100 \%$ & $100 \%$ & \\
\hline Position on Theatre List ${ }^{\S}$ & & & 0.300 \\
\hline $1^{\text {st }}$ & $31 \%$ & $30 \%$ & \\
\hline $2^{\text {nd }}$ & $32 \%$ & $36 \%$ & \\
\hline $3^{\text {rd }}$ & $26 \%$ & $24 \%$ & \\
\hline $4^{\text {th }}$ & $10 \%$ & $9 \%$ & \\
\hline $5^{\text {th }}$ & $5 \%$ & $0 \%$ & \\
\hline Post-operative blood transfusion (n) & 0 & 0 & \\
\hline D/C Maximum Flexion Angle $*$ & $80^{\circ}[60-100]$ & $80^{\circ}[65-105]$ & 0.795 \\
\hline Outpatient Physiotherapy referrals on $\mathrm{D} / \mathrm{C}$ & $18 \%$ & $19 \%$ & \\
\hline
\end{tabular}


Table 5: Six week and one year follow up. Data presented as median [range]

\begin{tabular}{|c|c|c|c|c|}
\hline Appointment & Variable & PCEA & LIA & $\begin{array}{c}\mathbf{P} \\
\text { Value }\end{array}$ \\
\hline \multirow{3}{*}{$\begin{array}{l}\text { Six weeks } \\
\text { post-op }\end{array}$} & Maximum flexion & $\begin{array}{c}\mathrm{n}=108 \\
95^{\circ}\left[50 \text { to } 120^{\circ}\right]\end{array}$ & $\begin{array}{c}n=113 \\
100^{\circ}\left[20 \text { to } 120^{\circ}\right]\end{array}$ & 0.316 \\
\hline & $\mathrm{OKS}$ & $\begin{array}{c}n=109 \\
32[7 \text { to } 47]\end{array}$ & $\begin{array}{c}n=112 \\
34[12 \text { to } 47]\end{array}$ & 0.204 \\
\hline & Maximum flexion & $\begin{array}{c}n=103 \\
103^{\circ}\left[65 \text { to } 130^{\circ}\right]\end{array}$ & $\begin{array}{c}\mathrm{n}=105 \\
105^{\circ}\left[80 \text { to } 130^{\circ}\right]\end{array}$ & 0.720 \\
\hline & $\mathrm{OKS}$ & $\begin{array}{c}n=98 \\
41[14 \text { to } 48]\end{array}$ & $\begin{array}{c}n=104 \\
41[6 \text { to } 48]\end{array}$ & 0.915 \\
\hline $\begin{array}{l}\text { One year } \\
\text { post-op }\end{array}$ & $\begin{array}{l}\text { Change in OKS } \\
\text { from pre-op }\end{array}$ & $\begin{array}{c}n=92 \\
24[-20 \text { to } 38]\end{array}$ & $\begin{array}{c}n=98 \\
22[-3 \text { to } 40]\end{array}$ & 0.640 \\
\hline
\end{tabular}




\section{Acknowledgements}

Sincere thanks to the Acute Pain Nurses, Physiotherapy staff and Arthroplasty Practitioners for collection of data throughout this trial.

\section{Declaration of interest}

No benefits in any form have been received or will be received from a commercial party related directly or indirectly to the subject of this article.

\section{Funding}

No Funding was received in completion of this trial 
Figure 1. CONSORT Flow Diagram 
Figure 2. Proportion of patients discharged from Rehabilitation per post-operative day 